\title{
Cognitive Function in Ambulatory Patients with Systolic Heart Failure: Insights from the Warfarin versus Aspirin in Reduced Cardiac Ejection Fraction (WARCEF) Trial
}

Trial. PLOS ONE 9(11): e113447. doi:10.1371/ journal.pone.0113447

Editor: Yoshihiro Fukumoto, Kurume University School of Medicine, Japan

Received: July 26, 2014

Accepted: October 24, 2014

Published: November 26, 2014

Copyright: (c) 2014 Graham et al. This is an open-access article distributed under the terms of the Creative Commons Attribution License, which permits unrestricted use, distribution, and reproduction in any medium, provided the original author and source are credited.

Data Availability: The authors confirm that all data underlying the findings are fully available without restriction. By arrangement with the sponsor, the NINDS, WARCEF data are housed at the Statistical Analysis Center in the Department of Biostatistics at Columbia University. We confirm that our data are available upon request. Data requests can be addressed to Dr. Shunichi Homma and the WARCEF Executive Committee, who can be contacted atsh23@cumc.columbia.edu.

Funding: The WARCEF trial was supported by grant \#s U01-NS-043975 to S Homma, and U01NS-039143 to JLP Thompson from the National Institute of Neurological Diseases and Stroke. Warfarin and warfarin placebo were provided by Taro Pharmaceuticals USA, and aspirin and aspirin placebo by Bayer HealthCare. The funders had no role in study design, data collection and analysis, decision to publish, or preparation of the manuscript

Competing Interests: Dr. Homma reports receiving payment from AGA Medical (now St. Jude Medical) for his work as a member of a data and safety monitoring board and consulting fees from Boehringer Ingelheim; Dr. Levin reports receiving consulting fees from United Healthcare; Dr. Teerlink reports receiving consulting fees from Amgen and grant support from Amgen, Cytokinetics, and Novartis on behalf of himself and from NovaCardia/ Merck on behalf of himself and his institution; Dr. Graham reports owning stock in March Pharmaceuticals, Medtronic, and Pfizer; Dr. Labovitz reports receiving grant support from Boehringer Ingelheim on behalf of his institution,

Susan Graham ${ }^{1}$, Siqin $\mathrm{Ye}^{2}$, Min Qian ${ }^{3}$, Alexandra R. Sanford ${ }^{3}$, Marco R. Di Tullio ${ }^{2}$, Ralph L. Sacco ${ }^{4}$, Douglas L. Mann ${ }^{5}$, Bruce Levin ${ }^{3}$, Patrick M. Pullicino ${ }^{6}$, Ronald S. Freudenberger $^{7}$, John R. Teerlink ${ }^{8}$, J. P. Mohr ${ }^{9}$, Arthur J. Labovitz ${ }^{10}$, Gregory Y. H. Lip $^{11}$, Conrado J. Estol ${ }^{12}$, Dirk J. Lok ${ }^{13}$, Piotr Ponikowski ${ }^{14}$, Stefan D. Anker ${ }^{15}$, John L. P. Thompson ${ }^{3}$, Shunichi Homma ${ }^{3 *}$ for the WARCEF Investigators

1. Division of Cardiology, Department of Medicine, State University of New York Upstate Medical University, Buffalo, New York, United States of America, 2. Division of Cardiology, Department of Medicine, Columbia University Medical Center, New York, New York, United States of America, 3. Department of Biostatistics, Columbia University Mailman School of Public Health, New York, New York, United States of America, 4. Department of Neurology, University of Miami Miller School of Medicine, Miami, Florida, United States of America, 5. Department of Medicine, Washington University, St. Louis, Missouri, United States of America, 6. Kent Institute of Medicine and Health Sciences, University of Kent, Canterbury, United Kingdom, 7. Division of Cardiology, Department of Medicine, Lehigh Valley Hospital, Allentown, Pennsylvania, United States of America, 8. Section of Cardiology, Department of Medicine, San Francisco Veterans Affairs Medical Center, University of California San Francisco, San Francisco, California, United States of America, 9. Department of Neurology, Columbia University Medical Center, New York, New York, United States of America, 10. Department of Cardiovascular Medicine, University of South Florida, Tampa, Florida, United States of America, 11. University of Birmingham Centre for Cardiovascular Sciences, City Hospital, Birmingham, United Kingdom, 12. Centro Neurológico de Tratamiento y Rehabilitación, Buenos Aires, Argentina, 13. Department of Cardiology, Deventer Hospital, Deventer, Overijssel, The Netherlands, 14. Department of Heart Diseases, Wroclaw Medical University, Military Hospital, Wroclaw, Lower Silesia, Poland, 15. Department of Innovative Clinical Trials, University Medical Centre Göttingen, Göttingen, Lower Saxony, Germany

\section{*sh23@columbia.edu}

\section{Abstract}

We sought to determine whether cognitive function in stable outpatients with heart failure (HF) is affected by HF severity. A retrospective, cross-sectional analysis was performed using data from 2, 043 outpatients with systolic HF and without prior stroke enrolled in the Warfarin versus Aspirin in Reduced Cardiac Ejection Fraction (WARCEF) Trial. Multivariable regression analysis was used to assess the relationship between cognitive function measured using the Mini-Mental Status Exam (MMSE) and markers of HF severity (left ventricular ejection fraction [LVEF], New York Heart Association [NYHA] functional class, and 6-minute walk distance). The mean (SD) for the MMSE was 28.6 (2.0), with $64(3.1 \%)$ of the 2,043 patients meeting the cut-off of MMSE $<24$ that indicates need for further evaluation of 
lecture fees from Boehringer Ingelheim, and fees for the development of educational presentations from the American College of Cardiology; Dr. Anker reports receiving consulting fees from Amgen, Bosch Healthcare, GlaxoSmithKline, Helsinn, LoneStar Heart, Novartis, Professional Dietetics, PsiOxus, Relypsa, SHL Telemedicine, and Thermo Fisher, grant support from Vifor Pharma, and lecture fees from Novartis, holding patents with Brahms AG and Charité Berlin, and receiving royalties from Imperial College; Dr. Ponikowski reports receiving consulting fees from Bayer, Boehringer Ingelheim, Coridea, Corthera, Johnson \& Johnson, Pfizer, Respicardia, and Vifor Pharma, grant support from Vifor Pharma on behalf of himself and his institution, and lecture fees from Abbott, Boehringer Ingelheim, Merck Serono, Pfizer, Respicardia, Sanofi-Aventis, Servier, and Vifor Pharma; and Dr. Lip reports receiving consulting fees from Astellas, AstraZeneca, Bayer, Biotronik, Boehringer Inhelheim, Bristol-Myers Squibb, Pfizer, Merck, Portola, and Sanofi-Aventis speakers bureau fees from Bayer, Bristol-Myers Squibb, Pfizer, Boehringer Ingelheim, and SanofiAventis, and payment for the development of educational presentations from Bayer, Boehringer Ingelheim, and Merck. No other potential conflict of interest relevant to this article was reported. This does not alter the authors' adherence to PLOS ONE policies on sharing data and materials.

- Membership of the WARCEF Committees and Investigators is provided in the Acknowledgments cognitive impairment. After adjustment for demographic and clinical covariates, 6 -minute walk distance $(\beta$-coefficient $0.002, p<0.0001$ ), but not LVEF or NYHA functional class, was independently associated with the MMSE as a continuous measure. Age, education, smoking status, body mass index, and hemoglobin level were also independently associated with the MMSE. In conclusion, six-minute walk distance, but not LVEF or NYHA functional class, was an important predictor of cognitive function in ambulatory patients with systolic heart failure.

\section{Introduction}

Reduced cognitive function is common in patients with heart failure,[1-9] and the ensuing impairment of executive function, memory and attention can adversely affect patients' quality of life and capacity for self-care. $[\underline{8}, \underline{10}]$ In addition to comorbidities such as hypertension and diabetes and psychosocial factors such as depression, [11] decreased cerebral perfusion due to cardiac dysfunction has been proposed as a key mechanism for the association between heart failure and cognitive impairment.[2, $\underline{3}, 10-12]$ Supporting this hypothesis, imaging studies have demonstrated organic changes in brain areas responsible for cognitive and executive functions in patients with heart failure, [13] and have shown that cardiac index is negatively associated with markers of brain aging in healthy individuals. [12] Furthermore, it has been suggested that heart failure severity can be an important predictor of cognitive function. $[\underline{2}, \underline{5}, \underline{6}, \underline{10}]$ However, many of these studies have important limitations, including small sample sizes [5] and potential confounding due to the restriction of enrollment to hospitalized or elderly individuals. $[1,2,4,6,7]$ A better understanding of how heart failure status affects cognitive function is thus needed, and can potentially provide insights to improve chronic management of heart failure.

The Warfarin versus Aspirin in Reduced Cardiac Ejection Fraction (WARCEF) trial, [14] which followed a broad range of individuals with medically managed chronic systolic heart failure who were in sinus rhythm, provides a unique opportunity to address this gap in knowledge. We undertook the present analysis of the WARCEF trial to characterize the predictors of cognitive status as measured by the Mini-Mental State Examination (MMSE), and to determine whether there is an independent association between cognitive function and measures of heart failure severity, as measured by left ventricular ejection fraction (LVEF), New York Heart Association (NYHA) functional class, and 6-minute walk distance.

\section{Methods}

The protocol for the randomized, double blinded WARCEF trial (http://www. ClinicalTrials.gov No. NCT00041938) has been described previously. [14, 15] 
Briefly, patients with left ventricular ejection fraction (LVEF) $\leq 35 \%$ and who were in sinus rhythm at time of enrollment were randomized to receive warfarin (target INR 2.75, with acceptable target range of 2.0 to 3.5) or aspirin (325 mg daily). Additional eligibility criteria included being 18 years or older, having no contraindications to warfarin therapy, having a modified Rankin score of 4 or less (on a scale of 0 to 6, with higher scores indicating more severe disability), and treatment with a beta blocker, an angiotensin-converting-enzyme (ACE) inhibitor or angiotensin-receptor blocker (ARB), or hydralazine and nitrates. Patients were excluded if they had a clear indication for warfarin or aspirin, or if they had a condition that conferred a high risk of cardiac embolism, such as atrial fibrillation, a mechanical cardiac valve, endocarditis, or an intracardiac mobile or pedunculated thrombus. Patients were also excluded if they were unable to follow an outpatient study protocol, or if they were unable to provide informed consent. Patients in any NYHA functional class were eligible, although patients in NYHA class I could account for no more than $20 \%$ of the total sample. A total of 2,305 participants were recruited from 168 centers in 11 countries from October 2002 to January 2010. The investigation conforms with the principles outlined in the Declaration of Helsinki, [16] and the study was approved by Institutional Review Boards at the coordinating centers for all sites. All subjects provided informed consent. For this analysis, we further excluded 248 participants with prior ischemic stroke, and 14 others who did not have complete MMSE assessment. The final sample for analysis thus included 2,043 participants.

\section{Cognitive Function, Heart Failure Severity, and Other Covariates}

All data used for this analysis were collected at time of enrollment for the WARCEF trial. The primary outcome of this post hoc analysis was cognitive function using the MMSE at the time of enrollment. The MMSE is a brief, validated, 30-point questionnaire commonly used to screen for cognitive impairment. [17] In the WARCEF trial, the MMSE was administered in a standardized fashion in the native language of each participant by trained staff at each individual site. Importantly, results of the MMSE were not directly used to determine patient eligibility for the WARCEF trial.

For this analysis, measures of heart failure severity included LVEF (measured by quantitative echocardiography or radionuclide or contrast ventriculography), 6minute walk distance, $[\underline{18}, 19]$ and NYHA functional class. LVEF measurements were obtained by central reading of tests performed at participating study sites by experienced observers blinded to randomization status of trial participants. For each participant, 6-minute walk distance was obtained by study coordinators who measured distance walked over a 6-minute period following a standardized protocol, [18] and NYHA functional class was determined on the basis of selfreported symptoms by investigators at each study site.

Additional baseline demographic covariates that were collected include age, sex, and education level (dichotomized for the current analysis as less than high school or high school graduate and above). Health behaviors were assessed by self-report 
at time of enrollment, including smoking status (never, former, or current smokers) and alcohol consumption (never, former consumption of $>2 \mathrm{oz} / \mathrm{day}$, or current consumption of $>2 \mathrm{oz} /$ day). Clinical covariates were determined at the initial study visit, including medical comorbidities (history of atrial fibrillation, hypertension, diabetes mellitus, ischemic cardiomyopathy), medications (betablockers and ACE-inhibitors/ARBs), body mass index (weight in kilograms divided by height in meters squared), baseline systolic blood pressure, and serum creatinine and hemoglobin levels (measured within 30 days of study enrollment).

\section{Statistical Analysis}

Descriptive statistics were provided for baseline MMSE, heart failure severity measures, and demographic and clinical covariates described above. We further calculated the proportion of patients with a MMSE of $<27$, the cut-off for abnormal cognitive function, and the proportion of patients with a MMSE of $<24$, a cut-off commonly used to indicate need for further evaluation of significant cognitive impairment. [20] For subsequent regression analyses, the MMSE was treated as a continuous variable as it was clustered around higher scores in the WARCEF population. Univariable regression analysis was performed with the MMSE as the dependent variable and individual predictors, including heart failure severity measures and other demographic and clinical covariates, as independent variables. Subsequently, all predictors were entered into a multiple regression model with the MMSE as the dependent variable. For all regression analyses, NYHA functional classes III and IV were combined due to the small number of participants with NYHA functional class IV. For continuous covariates, the regression $\beta$-coefficient represents the expected point-increase in mean MMSE for every one-unit increase of the covariate. For categorical covariates, the regression $\beta$-coefficient represents the difference in mean MMSE between the current category and the reference category. There was $9 \%$ (180/ 2043) missing data on 6-minute walk distance, $8 \%$ (166/2043) on hemoglobin, and 3\% (58/2043) on hypertension; less than 10 values were missing on all other variables. Therefore, multiple imputation was used to account for missing covariate data. Specifically, we created five data sets using a sequential regression imputation method, [21] performed regression analyses on each data set, and subsequently combined the results to produce the reported regression $\beta$ coefficients and $t$-test based 95\% confidence intervals and $\mathrm{p}$-values using the method described by Rubin. [22] All statistical analyses were performed using SAS software (version 9.2; SAS Institute, Cary, NC).

\section{Results}

Among the 2,043 WARCEF patients included in this analysis, the mean (SD) age was $60.8(11.3)$ years, and $1634(80 \%)$ were male. Other demographic and clinical 
Table 1. Baseline characteristics of participants in the WARCEF trial included for analysis.

\begin{tabular}{|c|c|}
\hline & All patients $(N=2043)$ \\
\hline \multicolumn{2}{|l|}{ Cognitive function } \\
\hline MMSE, score & $28.6(2.0)$ \\
\hline Cognitive impairment (MMSE $<24)$ & $64 / 2043(3.1 \%)$ \\
\hline Cognitive impairment, adjusted for education* & $29 / 2043(1.4 \%)$ \\
\hline \multicolumn{2}{|l|}{ Heart Failure Severity Measures } \\
\hline Ejection fraction, \% & $24.6(7.6)$ \\
\hline 6 minute walk, $\mathrm{m}$ & $355.9(146.7)$ \\
\hline \multicolumn{2}{|l|}{ NYHA classification } \\
\hline 1 & $271 / 2034(13.3 \%)$ \\
\hline II & $1145 / 2034(56.3 \%)$ \\
\hline III & $594 / 2034(29.2 \%)$ \\
\hline IV & $24 / 2034(1.2 \%)$ \\
\hline \multicolumn{2}{|l|}{ Demographic covariates } \\
\hline Age, years & $60.8(11.3)$ \\
\hline Male gender & $1634 / 2043(80.0 \%)$ \\
\hline High school graduate or greater & $1147 / 2039(56.3 \%)$ \\
\hline \multicolumn{2}{|l|}{ Smoking status } \\
\hline Current smoker & $352 / 2042(17.2 \%)$ \\
\hline Former smoker & $1054 / 2042(51.6 \%)$ \\
\hline \multicolumn{2}{|l|}{ Alcohol consumption } \\
\hline Current consumption, $>2$ oz per day & $517 / 2042(25.3 \%)$ \\
\hline Previous consumption, $>2$ oz per day & $433 / 2042(21.2 \%)$ \\
\hline \multicolumn{2}{|l|}{ Medical comorbidities } \\
\hline History of atrial fibrillation & $77 / 2041(3.8 \%)$ \\
\hline Hypertension & $1186 / 1985(59.8 \%)$ \\
\hline Diabetes Mellitus & $616 / 2040(30.2 \%)$ \\
\hline Ischemic cardiomyopathy & $878 / 2039(43.1 \%)$ \\
\hline Body mass index, $\mathrm{kg} / \mathrm{m}^{2}$ & $29.2(6.0)$ \\
\hline Systolic blood pressure, $\mathrm{mmHg}$ & $123.5(18.6)$ \\
\hline Serum creatinine, $\mathrm{mg} / \mathrm{dL}$ & $1.2(0.3)$ \\
\hline Hemoglobin, g/dL & $14.1(1.5)$ \\
\hline \multicolumn{2}{|l|}{ Heart Failure Medication } \\
\hline Beta blocker & $1843 / 2042(90.3 \%)$ \\
\hline ACE-inhibitor or ARB & $2011 / 2041(98.5 \%)$ \\
\hline
\end{tabular}

Values are expressed as mean (SD) or number (\%), where appropriate.

${ }^{*}$ Cognitive impairment adjusted for education is defined as a MMSE score of $<20$ for patients with less than high school education, or $<24$ for high school graduates or above.

Abbreviations: MMSE, Mini-Mental State Examination; NYHA, New York Heart Association Class; ACE, angiotensin converting enzyme; $\mathrm{ARB}$, angiotensin receptor blocker.

doi:10.1371/journal.pone.0113447.t001

covariates are described in Table 1. Of note, a high proportion of participants were treated with evidence-based heart failure therapy, including $90.3 \%$ who were on beta-blockers and $98.5 \%$ who were on ACE-inhibitors or ARBs. 


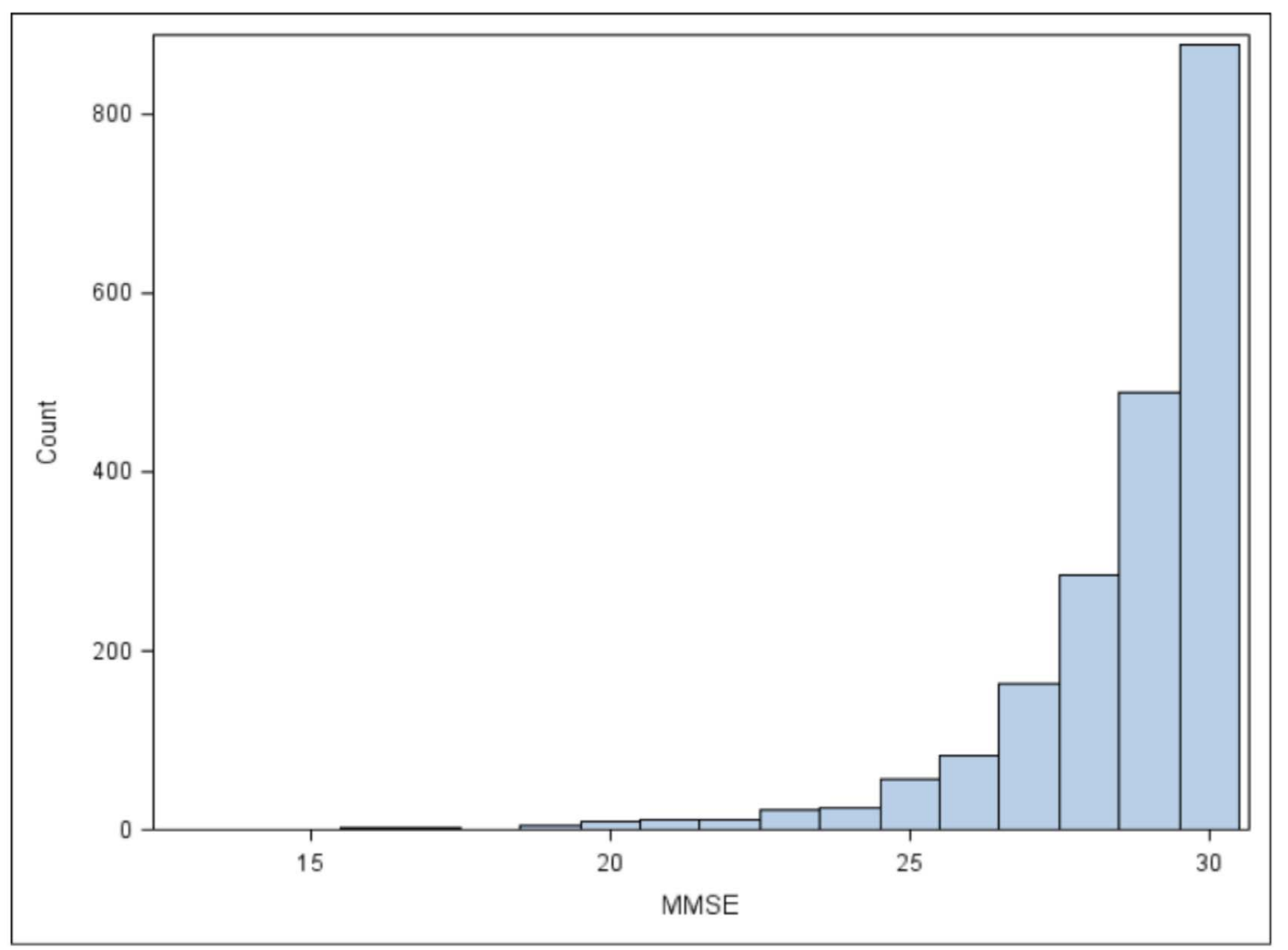

Figure 1. Distribution of the Mini-Mental Status Exam scores in WARCEF patients included for analysis.

doi:10.1371/journal.pone.0113447.g001

\section{Cognitive Function and Heart Failure Severity}

The distribution of the MMSE scores was skewed towards higher values, as shown in Figure 1. $228(11.2 \%)$ of 2043 patients had MMSE score of $<27$, suggestive of abnormal cognitive function, while $64(3.1 \%)$ patients had MMSE score of $<24$, indicating need for further evaluation of significant cognitive impairment. [20] For heart failure severity, the mean (SD) for LVEF was $24.6 \%(7.6 \%)$, and the mean (SD) distance for the 6-minute walk test was 356 meters (150 meters). Slightly more than two thirds of participants were in NYHA class I or II, with most of the remainder having NYHA class III symptoms. (Table 1).

\section{Univariable and Multivariable Determinants of Cognitive Function}

In univariable regression analysis, the MMSE score was significantly associated with both 6-minute walk distance $(\beta$-coefficient $0.002, \mathrm{p}<0.0001)$ and having NYHA class III or IV symptoms $(\beta$-coefficient $-0.460, \mathrm{p}=0.001)$, but not LVEF $(\beta$-coefficient $0.006, \mathrm{p}=0.264)$ (Table 2). Other predictors that were significant in univariable models included age, high school education or above, current or former smoking, current alcohol consumption of $>2$ oz per day, hypertension, diabetes mellitus, body mass index, and serum creatinine and hemoglobin levels. 
Table 2. Predictors of cognitive function (as measured by the Mini-Mental Status Exam) in univariable and multivariable regression models.

\begin{tabular}{|c|c|c|c|c|}
\hline & \multicolumn{2}{|c|}{ Univariable model (unadjusted) } & \multicolumn{2}{|l|}{ Multivariable model } \\
\hline & $\beta$-coefficient $(95 \% \mathrm{Cl})$ & p-value & $\beta$-coefficient $(95 \% \mathrm{CI})$ & $\begin{array}{l}\mathrm{p}- \\
\text { value }\end{array}$ \\
\hline \multicolumn{5}{|l|}{ Heart Failure Severity Measures } \\
\hline Ejection fraction, \% & $0.006(-0.005,0.018)$ & 0.264 & $0.007(-0.004,0.018)$ & 0.207 \\
\hline 6 minute walk, $\mathrm{m}$ & $0.002(0.002,0.003)$ & $<0.0001$ & $0.002(0.001,0.002)$ & $\begin{array}{l}<0.000- \\
1\end{array}$ \\
\hline \multicolumn{5}{|l|}{ NYHA classification } \\
\hline I & Ref & & Ref & \\
\hline II & $-0.128(-0.389,0.133)$ & 0.336 & $-0.031(-0.286,0.225)$ & 0.813 \\
\hline III or IV & $-0.460(-0.741,-0.179)$ & 0.001 & $-0.167(-0.451,0.117)$ & 0.250 \\
\hline \multicolumn{5}{|l|}{ Demographic covariates } \\
\hline Age, years & $-0.028(-0.036,-0.021)$ & $<0.0001$ & $-0.019(-0.027,-0.011)$ & $\begin{array}{l}<0.000- \\
1\end{array}$ \\
\hline Male gender & $0.132(-0.082,0.345)$ & 0.227 & $-0.136(-0.365,0.092)$ & 0.242 \\
\hline High school graduate or greater & $0.594(0.424,0.764)$ & $<0.0001$ & $0.511(0.342,0.680)$ & $\begin{array}{l}<0.000- \\
1\end{array}$ \\
\hline \multicolumn{5}{|l|}{ Smoking status } \\
\hline Never smoker & Ref & & Ref & \\
\hline Current smoker & $0.444(0.188,0.699)$ & 0.001 & $0.321(0.061,0.582)$ & 0.016 \\
\hline Former smoker & $0.201(0.007,0.394)$ & 0.042 & $0.204(0.009,0.399)$ & 0.041 \\
\hline \multicolumn{5}{|l|}{ Alcohol consumption } \\
\hline None & Ref & & Ref & \\
\hline Current consumption, $>2$ oz per day & $0.306(0.100,0.511)$ & 0.004 & $0.181(-0.025,0.386)$ & 0.085 \\
\hline Previous consumption, $>2$ oz per day & $-0.035(-0.253,0.184)$ & 0.756 & $-0.133(-0.355,0.088)$ & 0.239 \\
\hline \multicolumn{5}{|l|}{ Medical comorbidities } \\
\hline History of atrial fibrillation & $-0.186(-0.634,0.263)$ & 0.417 & $-0.056(-0.490,0.378)$ & 0.801 \\
\hline Hypertension & $-0.209(-0.384,-0.035)$ & 0.019 & $-0.124(-0.306,0.058)$ & 0.182 \\
\hline Diabetes Mellitus & $-0.265(-0.451,-0.080)$ & 0.005 & $-0.147(-0.336,0.043)$ & 0.130 \\
\hline Ischemic cardiomyopathy & $-0.123(-0.295,-0.050)$ & 0.163 & $0.041(-0.133,0.214)$ & 0.647 \\
\hline Body mass index, $\mathrm{kg} / \mathrm{m}^{2}$ & $0.021(0.007,0.035)$ & 0.003 & $0.015(0.000,0.031)$ & 0.047 \\
\hline Systolic blood pressure, $\mathrm{mmHg}$ & $0.0003(-0.004,0.004)$ & 0.897 & $0.002(-0.003,0.007)$ & 0.452 \\
\hline Serum creatinine, mg/dL & $-0.290(-0.552,-0.029)$ & 0.029 & $0.026(-0.246,0.298)$ & 0.853 \\
\hline Hemoglobin, g/dL & $0.160(0.104,0.215)$ & $<0.0001$ & $0.085(0.026,0.145)$ & 0.005 \\
\hline
\end{tabular}

For the multivariable model, the adjusted $\mathrm{R}^{2}$ was 0.073 .

doi:10.1371/journal.pone.0113447.t002

In the full multiple regression model, however, the only marker of heart failure severity that independently predicted the MMSE score was increased 6-minute walk distance $(\beta$-coefficient $0.002, \mathrm{p}<0.0001)$. Increasing age remained negatively associated with the MMSE after adjusting for other variables, while high school education or above, higher body mass index, current or former smoking status, and higher serum hemoglobin were positively associated with the MMSE score in the fully adjusted model. 


\section{Discussion}

In this retrospective, cross-sectional analysis of WARCEF participants with stable, medically managed systolic heart failure who were in sinus rhythm and who did not have prior ischemic strokes, we found that the only measure of heart failure severity that was independently associated with cognitive function was the 6minute walk distance: LVEF and NYHA functional class were not significant predictors of the MMSE score after adjustment for potential demographic and clinical confounders. Furthermore, younger age and higher educational status were both independently associated with higher MMSE scores, as was current or former smoking, body mass index, and serum hemoglobin level.

Our study extends the literature on the relationship between heart failure status and cognitive function. Previous studies have shown inconsistent associations between cognitive function and measures of heart failure severity such as LVEF and NYHA function class. $[\underline{5}, \underline{6}, \underline{23}]$ Although one study by Baldasseroni and colleagues demonstrated a positive association between 6-minute walk distance and cognitive function, their analysis was limited by a small sample size of only 80 elderly patients with heart failure. [24] In contrast, our analysis confirmed this relationship in a large sample of well-characterized, stable ambulatory heart failure patients. Furthermore, our results are also consistent with previous observations that cardiovascular fitness and exercise capacity are important determinants of cognitive function in both patients with heart failure [25] and the general population. [26] Taken together, our findings suggest that the 6-minute walk distance, which has been shown to be a powerful predictor of prognosis in patients with heart failure, $[\underline{18}, 27]$ is an objective indicator of heart failure status that was also strongly associated with cognitive function in this patient population.

Reduced cardiac output leading to decreased cerebral perfusion is thought to contribute to decreased cognitive function in patients with heart failure, $[\underline{3}, 12]$ but it is likely that other mechanisms also play a role in the relationship between 6-minute walk distance and cognitive function that we observed in WARCEF participants. The 6-minute walk distance integrates clinical and physiological aspects of general fitness, and comorbidities such as hypertension, diabetes, and atherosclerotic vascular disease could reduce both exercise capacity and cognitive function in patients with heart failure. [11] Nonetheless, although comorbidities such as hypertension and diabetes were associated with the MMSE for WARCEF patients in univariable analyses, these associations were no longer significant in the multivariable model, while the association between 6-minute walk distance and the MMSE remained. Given the limitations of the retrospective, crosssectional design of the current study, future research will need to confirm our findings and more precisely elucidate the mechanisms by which heart failure influences cognitive function.

In addition to the expected effect of age and education, we also found that hemoglobin level, body mass index, and current or former smoking status were independent predictors of the MMSE in this patient population. Anemia has 
previously been shown to be associated with cognitive dysfunction in elderly individuals. [28] Our results suggest that this relationship may also be true in patients with heart failure, potentially representing another mechanism for the increased risk of mortality and heart failure hospitalization conveyed by anemia that have been well-described in this patient population. [29] Similarly, low body mass index has been shown to correlate with cognitive decline, [30] and may reflect cardiac cachexia and increased vulnerability to cognitive dysfunction in patients with heart failure. It is however surprising that both current and former smokers had higher MMSE scores compared to never-smokers in our sample, a finding that contrasts with those from prior epidemiological studies. [31] We speculate that this may reflect confounding of the relationship between smoking status and the MMSE because of other factors, as current smokers were younger and had a lower prevalence of diabetes than non-smokers in our sample, and both current and former smokers had higher hemoglobin levels and lower systolic blood pressure than non-smokers (data not shown).

It is worth noting that in our sample of stable outpatients with heart failure, only a small proportion of patients had MMSE of $<27(11.2 \%)$ or $<24(3.1 \%)$. These findings are in contrast to prior studies suggesting that cognitive dysfunction could affect more than half of patients with heart failure. $[\underline{1}, \underline{2}, \underline{4}, \underline{6}, \underline{9}]$ A likely reason for this discrepancy is that, as in other heart failure clinical trials, most patients enrolled in WARCEF were younger than heart failure patients followed in the community. [32] Furthermore, the exclusion from our sample of patients who could not provide informed consent likely reduced the proportion of patients with significant cognitive impairment. The MMSE may also be relatively insensitive for detecting cognitive impairment in patients with heart failure, who may often have subtle deficits in cognitive domains such as recall and executive function. [9] Despite these limitations, however, our analysis was able to identify that the 6-minute walk distance is an independent predictor of higher MMSE in ambulatory heart failure patients.

There are several other limitations to our study. As a retrospective, secondary analysis of the WARCEF trial, our results are necessarily hypothesis generating. Since approximately $80 \%$ of WARCEF participants were male, our findings may also not be generalizable to female patients with heart failure. Furthermore, we analyzed data collected during the conduct of the WARCEF trial, and could not account for psychosocial factors such as depression that could influence assessment of cognitive function. Similarly, the WARCEF trial protocol did not include formal neuropsychiatric testing or invasive hemodynamic assessment, which are more definitive measurements of cognitive function and cardiac output, respectively. We assessed cognitive function at enrollment only, and the crosssectional design of this analysis does not allow us to determine whether improvement or deterioration of cognitive function may correlate with changes in heart failure status. [10] Finally, given the WARCEF trial only included heart failure patients in sinus rhythm, our findings cannot be extrapolated to individuals with heart failure and other arrhythmias. 


\section{Conclusion}

In this retrospective, cross-sectional analysis of stable, medically managed outpatients with systolic heart failure, we found that the 6-minute walk distance, a measure of heart failure severity, was an important predictor of cognitive function as measured by the MMSE. Our findings may be useful for future efforts to understand and treat cognitive impairment in this patient population.

\section{Acknowledgments}

We would like to acknowledge the following members of WARCEF committees and investigators:

WARCEF Committees and Investigators

\section{Executive Committee}

S. Homma, J.L.P Thompson, P. Pullicino, R. Freudenberger, S. Graham, J.

Teerlink, S. Ammon, D. Mann, J.P. Mohr, R.L. Sacco, B. Massie, S. Anker, A. Labovitz, and C. Moy

National Institute of Neurological Disorders and Stroke

C. Moy, P. Gilbert, L. Gutmann, and J. Marler; Clinical Coordinating Center: S. Homma, V. Mejia, A. Gabriel, S. Borden, E. Peña, C. Harris, R. Khadouri, D. Gohs, M. Brown, G. Berry, D. Disantis, M. Scullin, P. Smith, S. Kohsaka, W. Watson, and L. Guillory; Statistical Coordinating Center: J. L. P. Thompson, B. Levin, R. Buchsbaum, M. Del Valle, A. Sanford, G. Levy, K. Tea, J. Grier, L. Swydan, B. O’Hare, R. Prodhan, R. Arbing, E. Flanagan, E. Duverger, A. Peljto, W. Lo, A. Tierney, A. Henriquez, and J. Keen; Data and Safety Monitoring Board: G.J. del Zoppo, G.W. Albers, M. Eliasziw, J.A. Hinchey, K.C. Johnston, A.M. Lowe, I.L. Piña and J.A. Swain;

\section{Endpoint Adjudication Committee}

J.R. Teerlink, S. Ammon, S. Slomiak, and L. Cape; Neurology Adjudicators: H.J.M. Barnett, A. Bruno, J.D. Easton, S. Levine, and D. Sahlas; Cardiology Adjudicators: F. Bleyer, P. Carson, A. Ellis, A. Miller, and S.T. Palmeri; Core Echo Lab

A.Labovitz, M. Di Tullio, M.Bierig, R. Liu, and C. Donato; Hemorrhage adjudicator: R. Hart.

\section{Clinical Research Organizations}

Clinsys (United States and Canada): C. McKay, L. Wilson, E. Frey, K. Hayward, P. Stein-Beal and L. Konczarek; Charite (Germany, Poland and etherlands): M. Diek, M. Rohwedder, M. Bohdanowicz-Zazula, C.F. Peerenboom-Fey and M.

Vissiennon; Verum (Hungary and Ukraine): G. Rex, M. Varga, O. Kovtun and V. Orlyk; FGK (Czech Republic and Slovakia): P. Arenberger and J. Jaros. STAT

Research (Argentina): A. Ruiz, M. Zimmermann and A. Ellenberg.

\section{Complete list of WARCEF Sites}

The following institutions, investigators, and coordinators enrolled patients in the trial (shown in parenthesis is the number of patients randomized at the site): United States, LSU Health Sciences Center (66): A. Minagar, R. Kelley, J. McGee, 
P. Jinkins, and S. Bezucha; Buffalo General Hospital (53): S. Graham, V. Hart, M. Bonora, R. Sawyer, and K. Ammerman; Detroit VA Medical Center (50): P. Ramappa, V. Berchou, E. Jones, and E. Olgren; Denver VA Medical Center (38): B. Hattler, C. Anderson, B. Watson, and D. Wolf; UMDNJ - New Brunswick (29): J. Kosits, S. Palmeri, and L. Casazza; Mayo Clinic - Transplant Center (28): D. Yip, J. Meschia, A. McPhail, and K. Greenan; LeBauer Cardiovascular Research (28): R. Rothbart, J. Love, T. Schrader, and V. Garman; Louisville VA Medical Center (27): M. Stoddard, K. Remmel, and R. Longaker; UMDNJ - Newark (26): C. Gerula, M. Klapholz, J. Kirmani, and R. Mattessich; Columbia University Medical Center (24): M. Di Tullio, C. Rodriguez, and A. Gabriel; Reno VA Medical Center (22): W. Graettinger, A. Baker, and A. Valencia; Madison VA Medical Center (22): P. Kosolcharoen, and L. Williams; University of Arizona Health Sciences Center (21): V. Sorrell, B. Coull, and D. Bruck; Morehouse School of Medicine (20): E. Ofili, M. Frankel, and P. Jackson; Cardiac Care and Vascular Medicine, PLLC (20): M. Nanna, J. Yasen, S. Sparr, and W. Almeida; Long Island Jewish Medical Center (20): R. Libman, B. Stephens, and C. DeMers; Gulf Regional Research, LLC (20): T. Giles, L. Roffidal, and D. Barratt; Veterans Affairs Medical Center (19): M. Liston, C. Lindsey, and L. Giron; Virginia Commonwealth University (18): W. Felton III, L. Joseph, and M. Lee; University of Rochester Medical Center (16): J. Bisognano, C. Benesch, and L. Caufield; Santa Clara Medical Center (16): E. Nishime, M. Moussavian, and E. Polland; Black Hills Health Care System (16): L. Fischer, K. Peterson, and B. McGinnis; Lahey Clinic (15): M. Tilem, G. Allam, and J. Beebe; University of North Carolina at Chapel Hill (14): P. Chang, S. Sen, and C. Schuler; L.J. Chabert Medical Center (14): L. Arcement, M. Charlet, and E. Falgout; Sewickley Valley Medical Group, Cardiology (14): M. Malkowski, T. Dugan, and J. Hobbs-Williams; West Los Angeles VA Medical Center (14): A. Warner, K. Panizzon, and J. Johnson; Albert Einstein Medical Center (13): J. Dissin, D. Karia, and N. Molakala; Melbourne Internal Medicine Associates (11): B. Dandapani, R. Vicari, and E. Anthony; The Cleveland Clinic Foundation (11): I. Katzan, R. Hobbs, and A. Richmond; Denver Health Medical Center (11): R. Hughes, W. Baker, and M Applegate; Penn Presbyterian Medical Center (11): B. Drachman, S. Khella, and S. Donovan; Brooke Army Medical Center MCHE - MDC Cardiology Service (10): A. Slim, and D. Pearce Moore; Mount Sinai Medical Center (10): B. Darrow, and A. Travis; The Westchester Medical Group (10): A. Mercando, and R. Pellegrino; Salem VA Medical Center (10): N. Jarmukli, and T. Ochalek; St. Louis University Hospital (9): D. Janosik, and J. Dizes; University of Kentucky (9): L.C. Pettigrew, and D. Taylor; MetroHealth Medical Center (7): J. Hanna, and S. Bailey; Hackensack University Medical Center (7): R. Berkowitz, and S. Mathus; Huntington VA Medical Center (6) V. Virkud, and S. Shaw; Lehigh Valley Hospital (6): R. Freudenberger, and S. Nabhan; Winthrop University Hospital (5): E. Wirkowski, and B. George; Central Arkansas VA Medical Center (5): E. Smith, and S. Locke; Connecticut Heart and Vascular Center, PC (5): C. Landau, and D.Ferguson; University of Texas Medical School - Houston (5): H.V. Anderson, and L. Westbrook; Cincinnati VA Medical Center (5): M. Apelian, and S. Khoury; 
Berkshire Medical Center (5): J. Leppo, and T. Bator; Richmond VA Medical Center (4): W. Felton III, and M. Lee; University of Louisville (4): M. Stoddard, and R. Longaker; Oklahoma City VA Medical Center (4): U. Thadani, and J. Turner; Southern Arizona VA Health Care System (4): S. Goldman, and S. Daugherty; Methodist Heart, Lung and Vascular Institute (4): A. Adler, and T. Rennie; Tri-State Medical Group Cardiology (4): M. Malkowski, and D. Chupka; George Washington University (4): R. Katz, and L. Witkin; Rochester General Hospital (3): W. S. Burgin, and C. Weber; Penn State Milton S. Hershey Medical Center (3): J. Boehmer, and P. Frey; Kaleida Health Millard Fillmore Hospital (3): M. Wilson, and H. Tworek; Northport VA Medical Center (3): G. Mallis, and D. Mauceri; Holy Cross Medical Group (3): R. Schneider, and W. Schneider; Jackson Memorial Hospital (3): G. Ortiz, and M. Lichtenberger; Northeast Georgia Heart Center (3): B. Hott, and D. Patrick; Rush University Medical Center (2): S. Dunlap, and S.J. Kim; Fallon Clinic, Inc. (2): S. Pezzella, and D. Aubin; Temple University Hospital (2): L. Nikolaidis, and J. Wong; North Shore University Hospital (1): D. Leifer, and M. Rossi; Methodist Hospital - Physician Association (1): G. Torre, and J. Arredondo; Mayo Clinic Scottsdale (1): J. Lynch, and A. Metcalf; Watson Clinic Center for Research, Inc. (1): J. Gonzalez, and B. Donley; Hospital of the University of Pennsylvania (1): T. Cappola, and K. Craig; Houston VA Medical Center (1): B. Bozkurt, and M. Bolos; Blackstone Cardiology Associates (1): T. Noonan, and C. Alteri; Poland, Wroclaw Military Hospital (68): P. Ponikowski, L. Kowalczyk, A. Cwynar, D. Drazek, and J. Biegus; Specjalistyczny Szpital im dr A. Sokoloskiego (41): R. Szelemej, M. Jurczok, R. Serafin, and A. Jurczyk; Samodzielny Szpital Wojewodzki (33): M. Ogorek, D. Kopcik, B. Metzkier-Wyrwa, and A. Szczepanska; The Medical University of Warsaw (22): M. Dluzniewski, M. Modzelewski, W. Wicha, and M. Kuch; SP ZOZ Szpital Wojewodzki (22): K. Kuc, R. Piotrowski, and O. Lesniak; Spzoz Szpital Miejski Nr 2 (15): M. Krauze-Wielicka, J. Herman, and S. Nowakowska; Miedzyleski Szpital Specjalistyczny (15): T. Pasierski, B. Kozlowski, and K. Wolkowska; NZOZ Poradnia Kardiologiczna Centrum-Serce (11): A. Juszczak, J. Michalska, and I. Jedlinski; SCBK Pro Cordis (8): P. Miekus, and M. Konarzewski; SP ZOZ Klodzko (8): P. Berkowski, and N. Jacek; Slaskie Centrum Chorob Serca (8): Z. Kalarus, and A. Duszanska; Szpital Zespolony (5): J. Tarchalski, and P. Czaja; Medical University of Warsaw (5): Z. Gaciong, and J. Gora; SP Szpital Wojewodzki im. Papieza Jana Pawla II (2): A. Kleinrok, and G. Prokop-Lewicka; Canada, Ottawa Heart Institute (41): H. Haddad, R. Davies, L. Sitwell, and J. Donaldson; Etobicoke Cardiac Research Centre (29): T. To, R. Yufe, and B. Donelly; Montreal General Hospital (21): T. Huynh, R. Cote, and B. St. Jacques; Brampton Research Associates (20): D. Borts, G. Tullio, and A.M. Sindilar; Center for Neurologic Research (19): T. Winder, E. Janzen and C. Walker; St. Michael's Hospital (19): G. Moe, N. Bayer, and A. Konig; London Health Sciences Centre (14): M. Arnold, D. Spence, and J. Smith; Saint John Regional Hospital (13): R. Bessoudo, P. Bailey, and A. McNulty; Sudbury Cardiac Research (10): S. Nawaz, and C. Dewar; QE II Health Sciences Centre (10): M. Rajda, and M. MacFarlane; Jewish General Hospital (6): J. Minuk, and C. Schanz; Vancouver Island. 
Health Research Center (6): A. Penn, and L. Atkins; Montreal Heart Institute (4): A. Ducharme, and H. Brown; St. Boniface General Hospital (4): S. Zieroth, and A. Muñoz; Netherlands, Deventer Ziekenhuis Cardiologie Research (73): D. Lok, J.B.M. ten Holter, C. Huls, P. Bruggink-Andre, and A. van Bujisen-Nutters; Jeroen Bosch Ziekenhuis (39): M. Daniels, A. Coppes, M.van Zagten, and N. Elzebroek; Tweesteden Ziekenhuis (22): K. Hamroui, P. L. M. de Kort, and J. Vuijsters; Elisabeth Ziekenhuis (16): N. Holwerda, W. Hermans, and R. van der Loo; Medisch Spectrum Twente (14): E. Wajon, G. Hageman, and G. v. BuchemDamming; Reiner de Graaf Gasthuis (11): E. Ronner, A. Wissenburg-van Lieshout, and H. Niekus; Groene Hart Ziekenhuis (9): M.W.J. van Hessen, and G.A.M. Verheul; Twenteborg Ziekenhuis (2): G. Linssen, and L. te Pas; Ziekenhuis Hilversum (2): J. Plomp, and P.A.R. de Milliano; Medisch Centrum Leeuwarden (1): R. Breedveld, and M.J. Bos; Czech Republic, Kolin Hospital, Internal Dept. (44): M. Houra, D. Beran, and R. Lebedova; Trebic Kardiologicka Ambulance (20): J. Carda, E. Bednarova, and J. Vosmerova; Slany Municipal Hospital (17): G. Marcinek, T. Drasnar, and O. Najmanova; Litomysl Hospital, Internal Dept. (15): M. Dunaj, E. Pechackova, and M. Kuchar; Motol Faculty Hospital (14): P. Jansky, J. Simon, and H. Dvorakova; Prague Cardiological Clinic (13): P. Gregor, M. Maruskova, and L. Svoboda; Cardiology Outpatient Clinic Pilsen (13): Z. Lorenc, and P. Kralicek; Soukroma Kardiologická ambulance Opava (9): L. Pollak, Z. and M. Krobot; Brno Faculty Hospital, Internal and Cardiological Dept. (6): J. Spinar, and M. Nemec; St. Ann's Hospital Brno, (5): L. Spinarova, and R. Kuba; Prague Faculty Hospital Na Bulovce (3): F. Padour, and I. Padourova; Prague Homolka Hospital (3): M. Padour, and M. Michalova; The Charles University Hospital (3): L. Golan, and M. Hajkova; CARDIOMED s.r.o. (3): J. Povolny, and L. Krizova; Liberec District Hospital (2): D. Horak, and P. Kucera; IKEM Cardiological Clinic (2): I. Malek, and B. Krizova; Health Centre of Cardiology, Trutnov (1): J.

Svoboda, and R. Ferkl; Hungary, Karolyi Hospital (44): L. Regos, L. Csuros, O. Lovasz, and G. Kiss; Bacs-Kiskun County Hospital (31): S. Timar, N. Torok, and A. Hajnalne; Uzsoki Hospital (30): B. Palossy, A. Nagy, P. Fulop, and G. Jakab; Peterfy Hospital (13): A. Ronaszeki, M. Bodi, and M. Satori; Medical and Health Science Center, Debrecen (5): I. Edes, and I. Varga; Dr. Bugyi Istvan Hospital (5): A. Kovacs, and L. Berente; DRC Gyógyszervizsgáló Központ Kft. (5): E. Péterfai, and R. Pauer; Ferenc Jahn Hospital (4): K. Toth, and E. Nagy; Hetenyi Hospital (4): B. Benczur, and K Karsay; Erzsebet County Hospital (3): T. Végh, and R. Nagy; St. Stephan Hospital (3): P. Karpati, and Z. Davidovits; National Institute of Cardiology (2): J. Borbola, and J. Vanyi; Toldy Ferenc Hospital (2): B. Oze and A. Bujdoso; Veszprem megyei Csolnoky Ferenc Kórház-Rendelőintézet (1): I. Kosa, and L. Baliko; Germany, Medical Practice Dr. Natour (46): M. Natour, M. Morgil, E. Hartmann, and H. Morgil; Ludwigshafen Clinic (18): R. Winkler, S. Gass, and S. Baumann; Medical Practice Dr. Jeserich (18): M. Jeserich, J. Rodl, and M. Dzaiy; Charité Berlin (16): S. Anker, G. Turhan, and K. Wolf; Johannes Gutenberg University (10): S. Genth-Zotz, and T. Siebert; Medical Practice Dr. Jakobs (9): C. Jakobs, and M. Kiorwantsi; Georg August University (7): B. Pieske, and R. Wachter; Leipzig Medical Network (4): M. Schoenauer, and 
S. Voigt; Schleswig-Holstein University Hospital (4): H. Schunkert, and A. Boguschewski; Regensburg University Hospital (1): M. Resch, and R. Wensel; Gesellschaft fur Innovative Therapie (1): V. Schumann and P. Heidrich; Ukraine, National Medical University (27): O. Girina, Y. Prokopovych, M. Lebedynska, and I. Sorokina; City Clinical Hospital \#1, Kiev (21): O. Karpenko, N. Brodi, and S. Klochkov; M.D. Stazhesko Institute of Cardiology (17): L. Voronkov, Y. Besaga, and O. Novikova; Kyiv Central Clinical Hospital (12): K. Amosova, O.

Yaremenko, and K. Balaban; M.D. Strazhesko Institute of Cardiology of AMS (9): V. Kovalenko, and N. Polenova; Department Therapy of Stomatology faculty of National Medical University (9): I. Sakharchuk, and A. Ogorodnichuk; Kiev City Clinical Hosp of Ambulance (8): L. Rudenko, and Y. Tutov; M.D. Strazhesko Institute of Cardiology of AMS (6): A. Parkhomenko, and S. Kozhukhov; Odessa Municipal Clinical Hospital \#9 (4): E. Yakimenko, and S. Kolomiets; Odessa State Medical University (2): V. Yurlov, and S. Tikhonova; Argentina, Centro Neurologico de Tratamiento y Rehabilitacion (25): C. Estol, A. Elizalde, and B. Mangariello; CIPREC (12): C. Zaidman, and F. Guerlloy; Hospital Fernandez (11): P. Gitelman, K. Crotto, and S. Sassone; Grupo Medico Alem (11): J. Aiub, and F. Novoa; CICLO/Instituto de Cardiologia La Plata (10): R. Lopez Santi, and P. Romia; CEDIMBA (Ramos Mejia) (8): O. Montaña, and D. Malchik; Instituto Medico Adrogue (Centro Adrogue) (6): F. Sokn, and P. Schygiel; UAI Hospital Universitario (5): R. Porcile, and F. Soria Tito; Instituto Cardiovascular de Buenos Aires (2): J. Thierer, and P. Avellana; Sanatorio Itoiz, Avellaneda (2): C. Rapallo, and M. Calderon; United Kingdom, City Hospital, Birmingham (41): R.

MacFadyen, R. Haynes, and J. Partridge; Slovakia, III. Interna klinika, FNsP Nemocnica ak. L. Dérera (11): M. Kokles, S. Mehešová, and A. Zachar; KARDIOCENTRUM NITRA s.r.o. (11): M. Hranai, T. Varadyova, and T. Göbö; Kardiocentrum TN sro (5): J. Litvinova, and P. Loviska.

\section{Author Contributions}

Conceived and designed the experiments: SG SY JLPT SH. Performed the experiments: SG MRD RLS DLM PMP RSF JRT JPM AJL GYHL CJE DJL PP SDA. Analyzed the data: SY MQ AS BL JLPT. Wrote the paper: SG SY JLPT SH.

\section{References}

1. Cacciatore F, Abete P, Ferrara N, Calabrese C, Napoli C, et al. (1998) Congestive heart failure and cognitive impairment in an older population. Osservatorio Geriatrico Campano Study Group. J Am Geriatr Soc 46: 1343-1348.

2. Zuccala G, Onder G, Pedone C, Carosella L, Pahor M, et al. (2001) Hypotension and cognitive impairment: Selective association in patients with heart failure. Neurology 57: 1986-1992.

3. Gorelick PB, Scuteri A, Black SE, Decarli C, Greenberg SM, et al. (2011) Vascular contributions to cognitive impairment and dementia: a statement for healthcare professionals from the american heart association/american stroke association. Stroke 42: 2672-2713.

4. Dodson JA, Truong TT, Towle VR, Kerins G, Chaudhry SI (2013) Cognitive impairment in older adults with heart failure: prevalence, documentation, and impact on outcomes. Am J Med 126: 120-126. 
5. Hoth KF, Poppas A, Moser DJ, Paul RH, Cohen RA (2008) Cardiac dysfunction and cognition in older adults with heart failure. Cogn Behav Neurol 21: 65-72.

6. Trojano L, Antonelli Incalzi R, Acanfora D, Picone C, Mecocci P, et al. (2003) Cognitive impairment: a key feature of congestive heart failure in the elderly. J Neurol 250: 1456-1463.

7. Zuccala G, Marzetti E, Cesari M, Lo Monaco MR, Antonica L, et al. (2005) Correlates of cognitive impairment among patients with heart failure: results of a multicenter survey. Am J Med 118: 496-502.

8. Hajduk AM, Kiefe Cl, Person SD, Gore JG, Saczynski JS (2013) Cognitive change in heart failure: a systematic review. Circ Cardiovasc Qual Outcomes 6: 451-460.

9. Athilingam P, King KB, Burgin SW, Ackerman M, Cushman LA, et al. (2011) Montreal Cognitive Assessment and Mini-Mental Status Examination compared as cognitive screening tools in heart failure. Heart Lung 40: 521-529.

10. Kindermann I, Fischer D, Karbach J, Link A, Walenta K, et al. (2012) Cognitive function in patients with decompensated heart failure: the Cognitive Impairment in Heart Failure (Coglmpair-HF) study. Eur J Heart Fail 14: 404-413.

11. Vogels RL, Scheltens P, Schroeder-Tanka JM, Weinstein HC (2007) Cognitive impairment in heart failure: a systematic review of the literature. Eur J Heart Fail 9: 440-449.

12. Jefferson AL, Himali JJ, Beiser AS, Au R, Massaro JM, et al. (2010) Cardiac index is associated with brain aging: the Framingham Heart Study. Circulation 122: 690-697.

13. Woo MA, Kumar R, Macey PM, Fonarow GC, Harper RM (2009) Brain injury in autonomic, emotional, and cognitive regulatory areas in patients with heart failure. J Card Fail 15: 214-223.

14. Homma S, Thompson JL, Pullicino PM, Levin B, Freudenberger RS, et al. (2012) Warfarin and aspirin in patients with heart failure and sinus rhythm. N Engl J Med 366: 1859-1869.

15. Pullicino P, Thompson JL, Barton B, Levin B, Graham S, et al. (2006) Warfarin versus aspirin in patients with reduced cardiac ejection fraction (WARCEF): rationale, objectives, and design. J Card Fail 12: $39-46$.

16. World Medical Association (2013) World medical association declaration of helsinki: Ethical principles for medical research involving human subjects. JAMA 310: 2191-2194.

17. Folstein MF, Folstein SE, McHugh PR (1975) "Mini-mental state". A practical method for grading the cognitive state of patients for the clinician. J Psychiatr Res 12: 189-198.

18. Guyatt GH, Sullivan MJ, Thompson PJ, Fallen EL, Pugsley SO, et al. (1985) The 6-minute walk: a new measure of exercise capacity in patients with chronic heart failure. Can Med Assoc J 132: 919-923.

19. Cahalin LP, Mathier MA, Semigran MJ, Dec GW, DiSalvo TG (1996) The six-minute walk test predicts peak oxygen uptake and survival in patients with advanced heart failure. Chest 110: 325-332.

20. Lopez MN, Charter RA, Mostafavi B, Nibut LP, Smith WE (2005) Psychometric properties of the Folstein Mini-Mental State Examination. Assessment 12: 137-144.

21. Raghunathan TE, Lepkowski JM, Van Hoewyk JV, Solenberger $\mathbf{P}$ (2001) A multivariate technique for multiply imputing missing values using a sequence of regression models. Survey Methodology 27: 8595.

22. Rubin DB (1987) Multiple Imputation for Nonresponse in Surveys. New York: J. Wiley \& Sons.

23. Sauve MJ, Lewis WR, Blankenbiller M, Rickabaugh B, Pressler SJ (2009) Cognitive impairments in chronic heart failure: a case controlled study. J Card Fail 15: 1-10.

24. Baldasseroni S, Mossello E, Romboli B, Orso F, Colombi C, et al. (2010) Relationship between cognitive function and 6-minute walking test in older outpatients with chronic heart failure. Aging Clin Exp Res 22: 308-313.

25. Garcia S, Alosco ML, Spitznagel MB, Cohen R, Raz N, et al. (2013) Cardiovascular fitness associated with cognitive performance in heart failure patients enrolled in cardiac rehabilitation. BMC Cardiovasc Disord 13: 29 .

26. Colcombe S, Kramer AF (2003) Fitness effects on the cognitive function of older adults: a meta-analytic study. Psychol Sci 14: 125-130. 
27. Forman DE, Fleg JL, Kitzman DW, Brawner CA, Swank AM, et al. (2012) 6-Min Walk Test Provides Prognostic Utility Comparable to Cardiopulmonary Exercise Testing in Ambulatory Outpatients With Systolic Heart Failure. Journal of the American College of Cardiology 60: 2653-2661.

28. Terekeci HM, Kucukardali Y, Onem Y, Erikci AA, Kucukardali B, et al. (2010) Relationship between anaemia and cognitive functions in elderly people. Eur J Intern Med 21: 87-90.

29. Tang YD, Katz SD (2006) Anemia in chronic heart failure: prevalence, etiology, clinical correlates, and treatment options. Circulation 113: 2454-2461.

30. Cronk BB, Johnson DK, Burns JM (2010) Body mass index and cognitive decline in mild cognitive impairment. Alzheimer Dis Assoc Disord 24: 126-130.

31. Sabia S, Marmot M, Dufouil C, Singh-Manoux A (2008) Smoking history and cognitive function in middle age from the Whitehall II study. Arch Intern Med 168: 1165-1173.

32. Heiat A, Gross CP, Krumholz HM (2002) Representation of the elderly, women, and minorities in heart failure clinical trials. Arch Intern Med 162: 1682-1688. 